05,12

\title{
Нанопроволоки из сплавов FeNi и FeCo: синтез, структура и мёссбауэровские измерения
}

\author{
( И.М. Долуденко ${ }^{1}$, Д.Л. Загорский ${ }^{1, \uparrow}$, К.В. Фролов ${ }^{1}$, И.В. Перунов ${ }^{1}$, М.А. Чуев ${ }^{2}$, \\ В.М. Каневский ${ }^{1}$, Н.С. Ерохина ${ }^{1}$, С.А. Бедин ${ }^{1}$ \\ ${ }^{1}$ Институт кристаллографии ФНИЦ „Кристаллография и фотоника“ РАН, \\ Москва, Россия \\ ${ }^{2}$ Физико-технологический институт им. К.А. Валиева РАН, \\ Москва, Россия \\ ฯ E-mail: dzagorskiy@gmail.com
}

Поступила в Редакцию 26 марта 2020 г.

В окончательной редакции 26 марта 2020 г.

Принята к публикации 2 апреля 2020 г.

\begin{abstract}
Методом матричного синтеза на основе гальванического заполнения пор трековых мембран были получены нанопроволоки (НП) из сплавов $\mathrm{FeNi}$ и FeCo. Изучено изменение элементного состава НП при изменении состава электролита и при изменении потенциала осаждения. В НП из FeNi наблюдается эффект аномального соосаждения Fe: содержание железа в НП заметно выше, чем в электролите. Различие возрастает при увеличении исходной концентрации и при уменьшении ростового потенциала. Также обнаружено увеличение концентрации железа в вершинах НП. Для НП FеСо состав НП соответствует составу электролита и мало изменялся при изменении потенциала. Анализ рентгенодифракционных измерений позволил определить характер изменения спектров при варьировании условий роста. Обнаружена зависимость рентгеновских спектров FeNi от ростового потенциала - интенсивность пиков фаз изменяется. Мёссбауэровские измерения обнаружили спонтанную намагниченность для всех образцов массивов НП вдоль их осей. Впервые получена зависимость величины сверхтонкого магнитного поля $B_{h f}$ на ядрах ${ }^{57} \mathrm{Fe}$ от состава НП твердых растворов $\mathrm{Fe}_{x} \mathrm{Co}_{1-x}$ и $\mathrm{Fe}_{x} \mathrm{Ni}_{1-x}$. Обнаружено, что величина $B_{h f}$ уменьшается при возрастании скорости процесса электроосаждения (или при увеличении значения потенциала осаждения $U$ ).
\end{abstract}

Ключевые слова: нанопроволоки, матричный синтез, микроскопия, рентгеноструктурный анализ, магнитные свойства.

DOI: 10.21883/FTT.2020.09.49772.04H

\section{1. Введение}

Нанопроволоки (НП) являются уникальным типом наноструктур, перспективным в плане практических применений. Одним из способов получения массивов НП является метод матричного синтеза. Идея подхода состоит в заполнении калиброванных пор заранее подготовленной матрицы определенным веществом, образующим слепки (реплики) поровых каналов. И матрица, и вводимый в поры материал, и методы его введения могут быть различными. В настоящей работе получены металлические реплики - НП, для чего использовался метод гальванического заполнения пор в трековой мембране. Многоэтапность подхода (получение матрицы путем облучения полимерной пленки, вытравливание поровых каналов, их электролитическое заполнение) дает возможность управления процессом и варьирования состава и структуры, а, следовательно, и свойств получаемых материалов в широких пределах. Целью данного исследования являлось получение НП из сплавов $\mathrm{FeNi}$ и $\mathrm{FeCo}$ с различным соотношением элементов, а также исследование их структуры и свойств.

Впервые заполнение пор металлом было реализовано в работе [1], где автор гальванически заполнил оловом поры в слюде. Реплики из кобальта и ни- келя были получены авторами [2] в порах оксидной матрицы: было высказано предположение о возможности использования таких структур в магнитной записи. Применение полимерных трековых мембран (ТМ, или „ядерные фильтры“ ${ }^{6}$ в качестве ростовой матрицы было начато в 90-е годы прошлого столетия. Среди первых работ можно отметить $[3,4]$. В работе [5] изучено не только получение массивов НП, но и их магнитные свойства. Обзор работ по получению и исследованию НП, перспективы их применения на начало 90-х годов были приведены в известной работе [6]. В этот период основные работы проводились по электроосаждению НП из одного металла.

С конца 90-х годов началось активное использование другого типа матрицы - пористого оксида алюминия (ПОА) [7]. Однако значительная часть работ попрежнему проводится на полимерных ТМ. Отметим, что в подавляющем большинстве западных работ используется поликарбонатная (ПК) матрица, в то время как в России основным типом темплата является пористая пленка из полиэтилентерефталата (ПЭТФ, „лавсан“).

Вслед за получением НП из одного металла (однокомпонентных) последовали работы по получению многокомпонентных НП (как в матрицах из ТМ, так и в матрицах из ПОА). К числу преимуществ электрохи- 
мического метода относится возможность осуществлять различные типы процессов, изменяя их параметры в широких пределах. Так, метод дает возможность получения как гомогенных структур - т.н. НП из сплавов, так и гетерогенных НП, состоящих из чередующихся слоев различных металлов. Примеры возможных вариантов приведены во многих работах, например, в обзорах $[8,9]$. Ряд электрохимических особенностей происходящих в порах процессов описан в обзоре [10].

Особый интерес всегда вызывали НП из магнитных материалов группы железа. Такие НП интересны как с теоретической точки зрения (магнетизм в наноразмерных структурах), так и в плане возможных практических применений. К числу последних можно отнести создание миниатюрных магнитов и магнитопроводов, сенсоров (магнитных и не только), элементов спинтроники, поверхностей для магнитной записи высокой плотности. В [11] приведен обзор работ по изучению магнитных материалов и проведено сравнение магнитных характеристик $\mathrm{Fe}, \mathrm{Co}$ и Ni. B работах последних лет отмечаются и другие перспективы использования массивов магнитных НП. Так, в статье [12] исследовались НП из Fе и $\mathrm{Co}, \mathrm{Ni}$ в порах ПОА и была выявлена корреляция между конфигурацией НП и создаваемым ими магнитным полем.

Магнитные свойства таких структур зависят от параметров самого магнитного материала, от вытянутой формы проволоки, от взаимодействия между проволоками. Так, в [13] показано, что при меньшем расстоянии между проволоками увеличивается их дипольное взаимодействие и уменьшается „прямоугольность“ петли гистерезиса.

Для магнитных НП также можно отметить переход от простых, однокомпонентных НП к более сложным, многокомпонентным - т.н. „сплавам“. Последние образуются в процессе совместного гальванического осаждения (со-осаждения) двух или нескольких металлов. Из известной диаграммы зависимости магнитных свойств следует возможность получения сплавов с широко изменяющимися в зависимости от состава свойствами - как магнитомягкими, так и магнитожесткими. Однако диаграмма эта получена для объемных образцов и вопрос о ее применимости к наноразмерным объектам (в частности для массивов НП) остается открытым.

B работах $[14,15]$ FeСо НП с диаметрами от 100 и $300 \mathrm{~nm}$ были выращены в порах ПОА, были изучены их структура и магнитные свойства. Авторы $[16,17]$ описали получение $\mathrm{FeNi}$ различных диаметров НП в порах ПОА, а также их структуру, электрические и магнитные свойства.

Отметим, что отличительной особенностью практически всех зарубежных работ было использование мембран из ПОА. Однако известно, что многие требуемые параметры (например - гибкость матрицы, необходимая для т.н. „гибкой электроники“ или небольшая поверхностная плотность структурных единиц) - могут быть достигнуты с использованием другого типа матриц - трековых мембран. В работах авторов настоящей статьи НП из сплавов синтезировались именно в матрицах из полимерной пленки (ПЭТФ).
В работе [18] исследованы НП из $\mathrm{FeCo}$, полученные из электролита фиксированного состава $(\mathrm{Fe}: \mathrm{Co}=3: 1)$ элетроосаждением в поры с диаметрами от 30 до $200 \mathrm{~nm}$. Сравнивались различные потенциалы осаждения от 600 до $900 \mathrm{mV}$. Показана зависимость структурных данных и мёссбауэровских спектров от условий получения. В работе [19] НП из сплавов $\mathrm{FeCo}$ и $\mathrm{FeNi}$, были получены гальваническим осаждением в ТМ с порами от 30 до $200 \mathrm{~nm}$ при варьировании напряжения в достаточно узком интервале - от 600 до $800 \mathrm{mV}$. Проведены структурные и магнитометрические исследования. Показано, что и ростовое напряжение, и диаметры поровых каналов оказывают влияние на магнитные свойства получаемых НП.

В работе [20] получены FeNi HП с диаметрами 30 и $70 \mathrm{mV}$. Показано, что НП состоят их магнитных доменов размером около $20 \mathrm{mV}$ и их магнитные моменты ориентированы преимущественно вдоль оси НП. Методом мёссбауэровской спектроскопии были определены поля на ядре. Магнитные свойства таких систем были оценены с помощью обобщенной модели Стонера-Вольфарта.

Сравнение полученных результатов показывает, что параметры получаемых массивов НП могут сильно зависеть и от концентрации, и от условий роста, и от используемых ростовых матриц. Для многих экспериментов отмечается различие результатов различных работ и/или плохая повторяемость. Широко известен (и отмечается в ряде работ) эффект т.н. аномального соосаждения железа. Выявлено, что этот эффект при росте НП проявляется даже сильнее, чем при росте объемных образцов или пленок. В то же время, регулярных исследований влияния аномального со-осаждения железа на структуру и свойства НП нет.

Настоящая работа посвящена получению и исследованию НП из сплавов металлов группы железа - FeNi и FeCo. B ней предпринята попытка для этих двух типов широко распространенных НП детально изучить зависимость состава и свойств от концентрации электролита и потенциала осаждения. Для этого случая не решен ряд вопросов: насколько состав НП соответствует составу электролита? Влияет ли ростовой потенциал? Как состав получаемых НП влияет на их свойства? Ответам на эти вопросы и посвящена настоящая работа.

\section{2. Эксперимент}

Матрицы. Исследуемые в работе НП двух типов были получены с использованием полимерных матриц (трековых мембран, ядерных фильтров) со сквозными порами цилиндрического сечения. Были использованы „промышленные“ трековые мембраны (производства ОИЯИ, Дубна) со следующими параметрами: толщина пленки - $12 \mu \mathrm{m}$; диаметр пор $-100 \mathrm{~nm}$; плотность пор $-1.2 \cdot 10^{9}$ pore $/ \mathrm{cm}^{2}$. Для создания проводящего слоя поверхность мембраны металлизировалась: на первом этапе проводилось нанесение тонкого аморфного слоя меди методом термического распыления в вакууме 
(установка ВУП-4), на последующем этапе этот слой усиливался путем гальванического нанесения толстого слоя меди $(5-30 \mu \mathrm{m})$ на первый слой.

Электроосаждение. В работе применялись две серии электролитов: растворы для создания НП из сплавов $\mathrm{FeNi}$ содержали $\mathrm{NiSO}_{4} \cdot 7 \mathrm{H}_{2} \mathrm{O}-16 \mathrm{~g} / \mathrm{l} ; \mathrm{NiCl}_{2} \cdot 6 \mathrm{H}_{2} \mathrm{O}-$ $40 \mathrm{~g} / \mathrm{l}$. Концентрация $\mathrm{FeSO}_{4} \cdot 7 \mathrm{H}_{2} \mathrm{O}$ изменялась от 4 до $32 \mathrm{~g} / 1$. Данное изменение концентрации соответствовало изменению отношения ионов железа к никелю от 6 к $94 \%$ до 44 к $56 \%$.

Для создания НП из сплавов $\mathrm{FeCo}$ электролиты содержали $\mathrm{CoSO}_{4} \cdot 7 \mathrm{H}_{2} \mathrm{O}-16 \mathrm{~g} / \mathrm{l} ; \mathrm{CoCl}_{2} \cdot 6 \mathrm{H}_{2} \mathrm{O}-40 \mathrm{~g} / \mathrm{l}$. Концентрация $\mathrm{FeSO}_{4} \cdot 7 \mathrm{H}_{2} \mathrm{O}$ изменялась от 4 до $72 \mathrm{~g} / 1$, что соответствовало изменению соотношения ионов железа к никелю от 6\% до 53\%. Для большего увеличения относительной концентрации ионов железа концентрация солей кобальта снижалась в следующей последовательности - $\mathrm{CoSO}_{4} \cdot 7 \mathrm{H}_{2} \mathrm{O}-12 \mathrm{~g} / 1,8 \mathrm{~g} / 1,4 \mathrm{~g} / 1,2 \mathrm{~g} / 1,2 \mathrm{~g} / \mathrm{l}$; $\mathrm{CoCl}_{2} \cdot 6 \mathrm{H}_{2} \mathrm{O}-32 \mathrm{~g} / 1,24 \mathrm{~g} / 1,16 \mathrm{~g} / 1,8 \mathrm{~g} / 1,4 \mathrm{~g} / 1$. Этот прием позволил изменять относительную концентрацию ионов железа от $59 \%$ до $91 \%$.

Во всех случаях применялись следующие добавки: борная кислота $\mathrm{H}_{3} \mathrm{BO}_{3}-25 \mathrm{~g} / \mathrm{l}$, лаурилсульфат натрия - $1 \mathrm{~g} / 1$ (для увеличения смачиваемости пор) матрицы и аскорбиновая кислота - $1 \mathrm{~g} / 1$ (для предотвращения перехода двухвалентных ионов железа в трехвалентное состояние).

Процесс проводился в специальной гальванической ячейке, по двухэлектродной схеме. Площадь образца, на которую проводилось осаждение, составляла $2.5 \mathrm{~cm}^{2}$. Использовался анод из железа. В качестве источника применялся потенциостат-гальваностат Elins P-2X. Процесс проводился при постоянном потенциале (гальваностатический режим). Ростовое напряжение в работе на первом этапе составляло $1.5 \mathrm{~V}$, а на втором изменялось в пределах от 1 до $2 \mathrm{~V}$. Для контроля заполняемости пор в ходе процесса проводилась запись кривых зависимости тока от времени.

Электронная микроскопия. Для исследования образцов использовался сканирующий электронный микроскоп JEOL JSM 6000+. Работа проводилась в режиме вторичных электронов, при ускоряющем напряжении $15 \mathrm{kV}$.

Рентгеновская дифракция. Измерения выполнены на дифрактометре RIGAKU MiniFlex 600. Использовалось медное излучение $(\lambda=1.54 \AA)$, диапазон сканирования составлял $40-80^{\circ}$ с шагом в $0.01^{\circ}$ со скоростью $1^{\circ} / \mathrm{min}$.

Мёссбауэровская спектроскопия. Гамма-резонансные спектры поглощения на ядрах ${ }^{57} \mathrm{Fe}$ на образцах массивов HП $\mathrm{Fe}_{x} \mathrm{Ni}_{1-x}$ и $\mathrm{Fe}_{x} \mathrm{Co}_{1-x}$ были измерены при комнатной температуре $T=295 \mathrm{~K}$ на стандартном мёссбауэровском спектрометре МC-1104Ем в геометрии пропускания в режиме постоянных ускорений. Использовался источник гамма-квантов ${ }^{57} \mathrm{Co}(\mathrm{Rh})$. Изомерные сдвиги измерялись относительно стандартного поглотителя $\alpha$-Fe (железная фольга толщиной $30 \mu \mathrm{m}$ MRA.2.6 AO „РИТВЕРЦ““). Коллимированный поток гамма-излучения был направлен перпендикулярно плоскости полимерной мембраны таким образом, чтобы волновой вектор гаммаквантов $\mathbf{k}_{\gamma}$ совпадал по направлению с осью трековых пор и нанопроводов. Компьютерный анализ экспериментальных спектров был выполнен с помощью программного обеспечения Univem MS, поставляющегося со спектрометром МC-1104Ем, и DISCVER [21,22].

Магнитные измерения. Кривые намагничивания измерялись при комнатной температуре с помощью вибрационного магнитометра LakeShore 7407 с частотой $82 \mathrm{~Hz}$. Каждый образец с площадью поверхности около $1 \mathrm{~cm}^{2}$ фиксировался на плоском держателе, внешнее магнитное поле было направлено параллельно или перпендикулярно плоскости образца, что соответствовало ориентации осей НП в мембране $\left(\varphi=90^{\circ}\right)$ или $\left(\varphi=0^{\circ}\right)$. Величина магнитного поля изменялась от -5 до $5 \mathrm{kOe}$.

\section{3. Результаты и обсуждение}

Электроосаждение массивов нанопроволок. На первом этапе рост обоих типов $\mathrm{HП}(\mathrm{FeNi}, \mathrm{FeCo})$ проводился при напряжении $1.5 \mathrm{~V}$. Для определения времени необходимого для заполнения матрицы записывались зависимости силы тока от времени. Примеры полученных кривых приведены на рис. 1.

По резкому возрастанию тока можно было определить момент заполнения пор в матрице. В последующих экспериментах время роста составляло 90\% от времени, необходимого для полного заполнения матрицы.

На втором этапе исследовалась зависимость состава НП от потенциала осаждения. Для железоникелевых НП эксперимент проводился с тремя составами электролита. Эти составы были подобраны исходя из результатов предыдущей серии экспериментов: они соответствовали получению НП с $25 \%, 50 \%$ и $75 \%$ железа при ростовом потенциале 1.5 V. Для НП из $\mathrm{FeCo} \mathrm{такое} \mathrm{исследование}$ проводилось только для состава 50\%. Задача заключалась в выявлении влияния напряжения на элементный состав. Для этого для четырех вышеуказанных составов ростовое напряжение изменяли от 1 до $2 \mathrm{~V}$.

Микроскопия. После получения структура образцов исследовалась методами электронной микроскопии с элементным анализом. Для этого, путем стравливания в концентрированном растворе щелочи, от полученных массивов НП отделялась ростовая полимерная матрица. (При этом НП оставались „зафиксированными“ на общей подложке - ростовой основе). Примеры полученных СЭМ-изображений для обоих типов образцов приведены на рис. 2.

Легко видеть, что все НП имеют сходную топографию, определяемую геометрией пор. Можно отметить некоторое увеличение диаметра пор по сравнению с диаметром поровых каналов $(100 \mathrm{~nm})$. Последнее может объясняться „растяжением“ порового канала (внутренняя поверхность которого часто покрыта рыхлым гельслоем). 

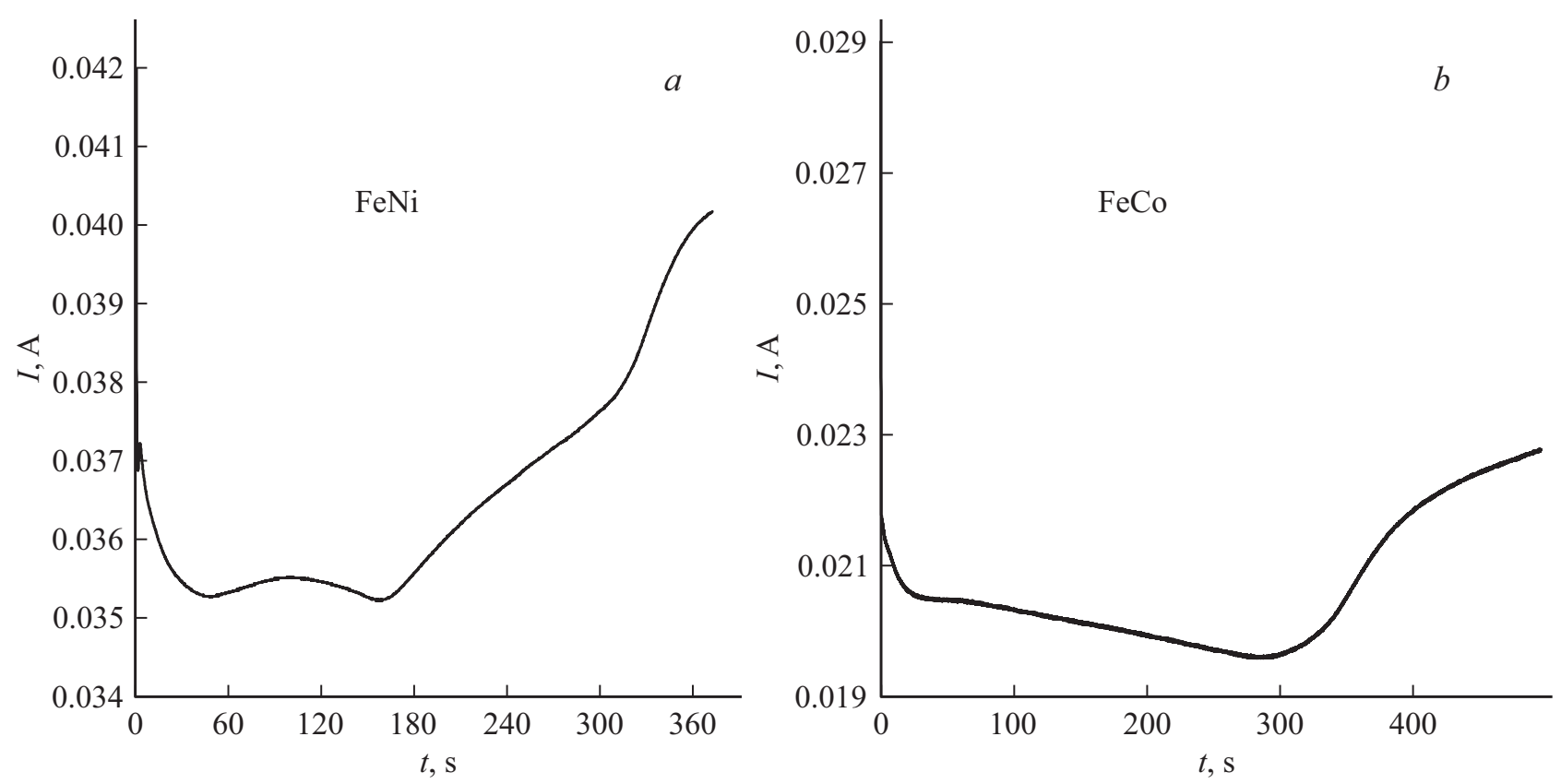

Рис. 1. Зависимость тока от времени при осаждении $\mathrm{FeNi}(a)$ и $\mathrm{FeCo}(b)$ образцов. Значения силы тока могут быть нормированы на площадь образцов $-2.5 \mathrm{~cm}^{2}$ с учетом пористости мембран $-7 \%$.

$a$
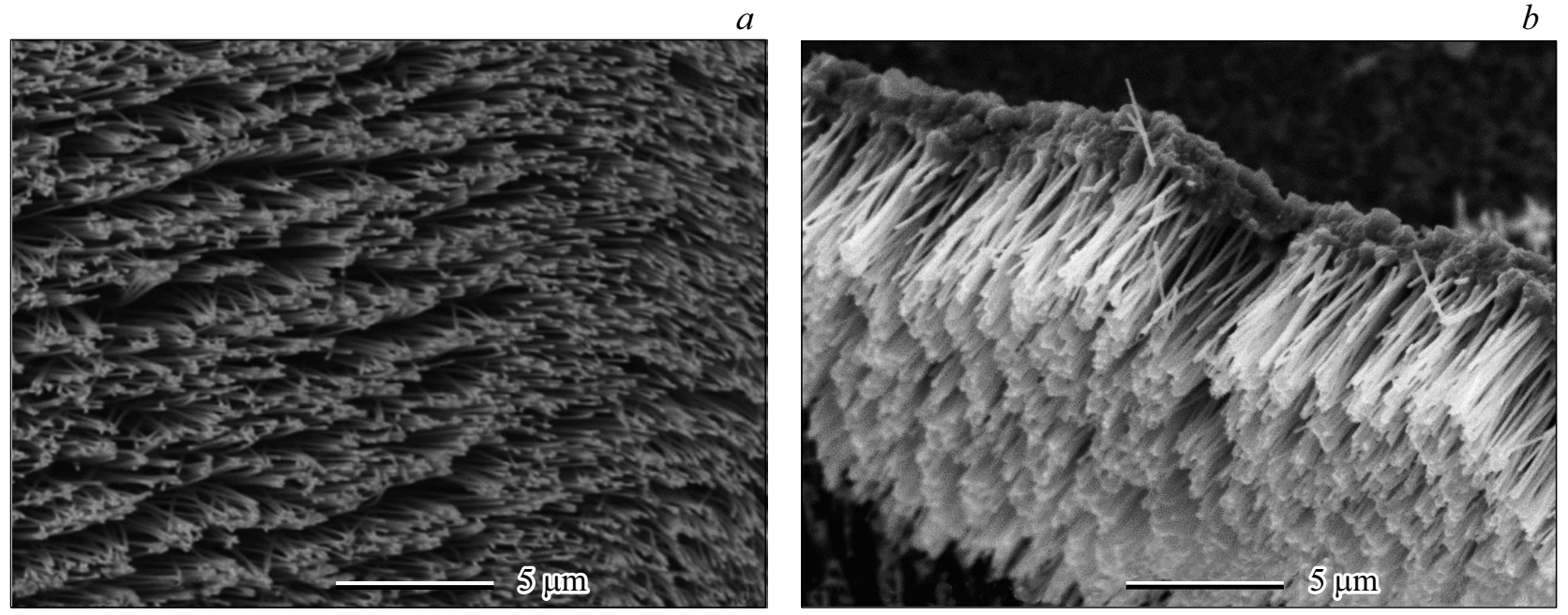

Рис. 2. СЭМ-изображение полученных массивов НП: $a) \mathrm{FeNi}, b$ FeCo.

Элементный состав. Полученные результаты для изменения состава как FeNi HП, так и FeCo НП в зависимости от состава электролита иллюстрирует рис. 3 .

Анализ полученных зависимостей выявляет заметное различие двух типов НП. Так, для НП из сплава FeCo содержание металлов в НП примерно соответствовало (в пределах точности эксперимента) их содержанию в электролите. В то же время, во всех НП из сплава $\mathrm{FeNi}$ содержание железа в НП превышало содержание железа в ростовом растворе (соответственно, менялось и содержание никеля). При этом с увеличением концентрации $\mathrm{Fe}$ различие составов возрастало от 10\% до $35 \%$. Этот результат, наблюдавшийся ранее для других железосодержащих составов, может объясняться эффектом аномального соосаждения железа.

Полученные во второй части работы зависимости (состава НП от потенциала осаждения) для FeNi представлены на рис. 4.

Приведенные графики демонстрируют значительную зависимость состава от напряжения: во всех случаях уменьшение напряжения приводит к увеличению содержания железа. Отметим, что этот эффект наиболее выражен для состава с минимальным содержанием железа (25\% при росте при потенциале $1.5 \mathrm{~V})$. Наблюдаемая зависимость является, очевидно, еще одним проявлением эффекта аномального соосаждения железа. 


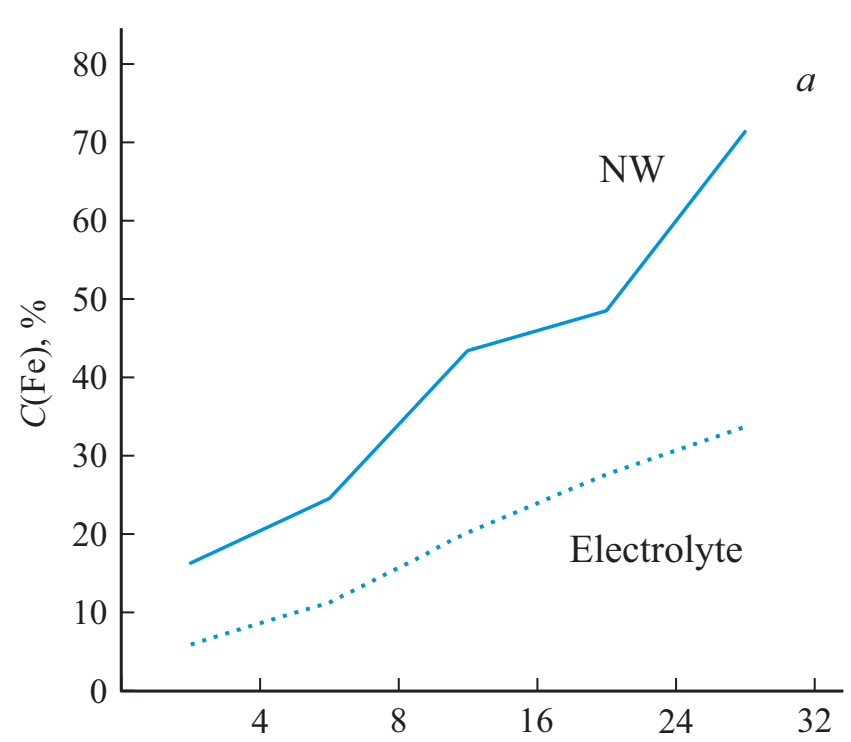

Concentration of $\mathrm{FeSO}_{4} \cdot 7 \mathrm{H}_{2} \mathrm{O}$ in the electrolyte, $\mathrm{g} / 1$

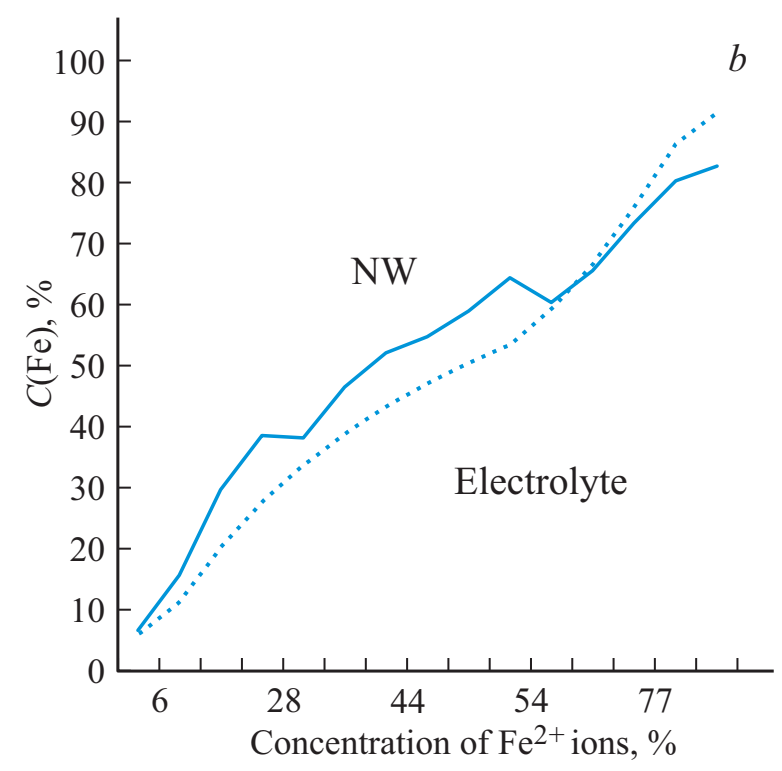

$b$

Рис. 3. Графики зависимости элементного состава НП от состава электролитов: $a$ ) FeNi, $b$ ) FeCo.

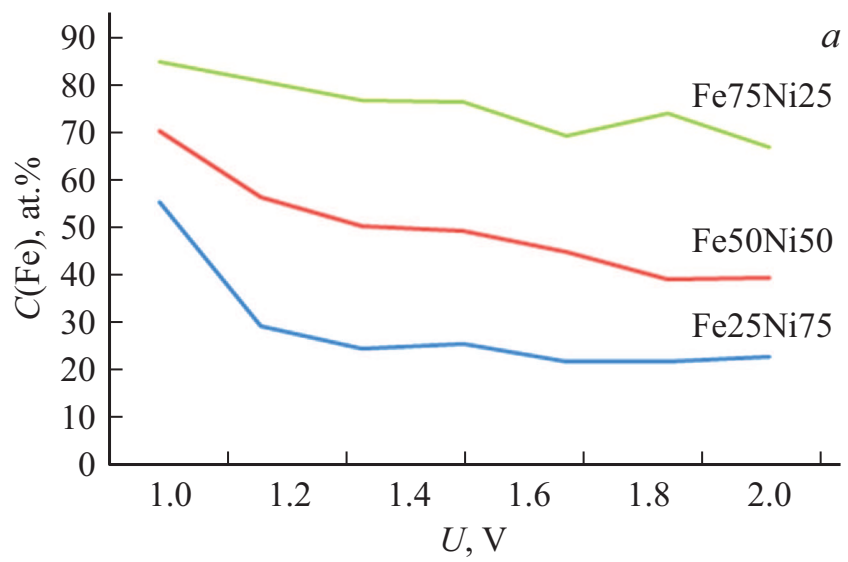

$a$

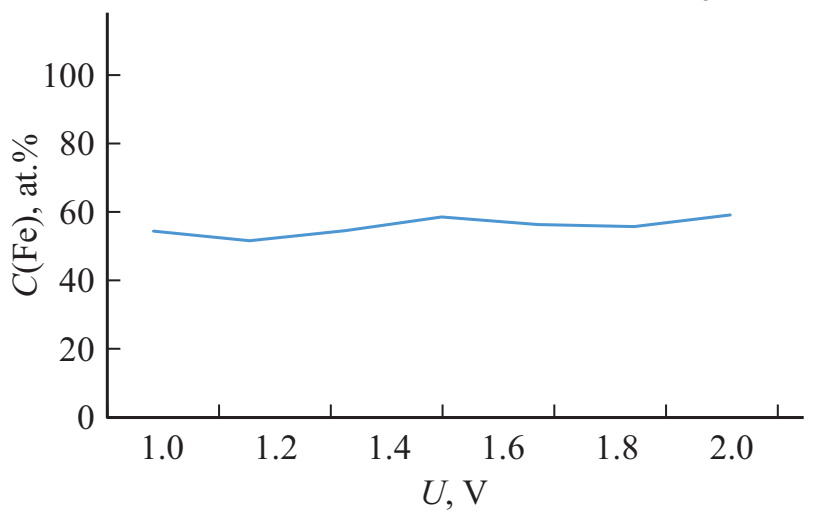

Рис. 4. Графики зависимости элементного состава FeNi HП от ростового напряжения $a$ ) для трех типов исходных составов FeNi, b) для FеСо с соотношением элементов 50/50 при 1,5 V.

Аналогичным образом проводилось и изучение зависимости состава FеСо НП от потенциала осаждения. Проведено исследование влияния изменения напряжения при использовании электролита, дающего равные концентрации металлов (т.е. 50\% Fе и 50\% Со) при потенциале осаждения $1.5 \mathrm{~V}$. Данные представлены на рис. $4, b$. Из полученных результатов можно сделать вывод о том, что изменение напряжения (по крайней мере от 1 до $2 \mathrm{~V}$ ) не оказывает заметного влияния на изменение состава.

Так же было исследовано распределение элементов по длине НП; доказано, что для НП из сплавов $\mathrm{FeNi}$ состав изменяется - различия для двух „концов“ НП составляют порядка 7\%: концентрация Fе увеличивается с приближением к „вершине“ НП. Напротив, для $\mathrm{FeCo}$ соотношение элементов вдоль оси НП (по мере заполнения матрицы) не изменяется.
Рентгеноструктурный анализ. Проведены оценочные рентгеноструктурные исследования обоих типов образцов. Исследовались зависимости кристаллической структуры образцов от ростового напряжения. Полученные для обоих типов НП рентгенограммы приведены на рис. 5. Так, образцы FeNi были получены с использованием электролита с содержанием $\mathrm{FeSO}_{4} \cdot 7 \mathrm{H}_{2} \mathrm{O}-8 \mathrm{~g} / \mathrm{l}$. (НП, выращенные из этого электролита при напряжении $1.5 \mathrm{~V}$ имели состав $25 \% \mathrm{Fe}$ и $75 \% \mathrm{Ni}$ ). Была получена серия образцов, рост которых проводился при различных потенциалах - от 1 до 2 V. Пример результатов, полученных для крайних значений потенциалов $-1 \mathrm{~V}$ и $2 \mathrm{~V}$ - приведен на рис. $5, z$.

Анализ рентгенограмм показывает, что во всех случаях FeNi НП состоят из твердых растворов на основе железа. Можно предположить существование двух фаз, соответствующих твердым растворам FeNi c от- 

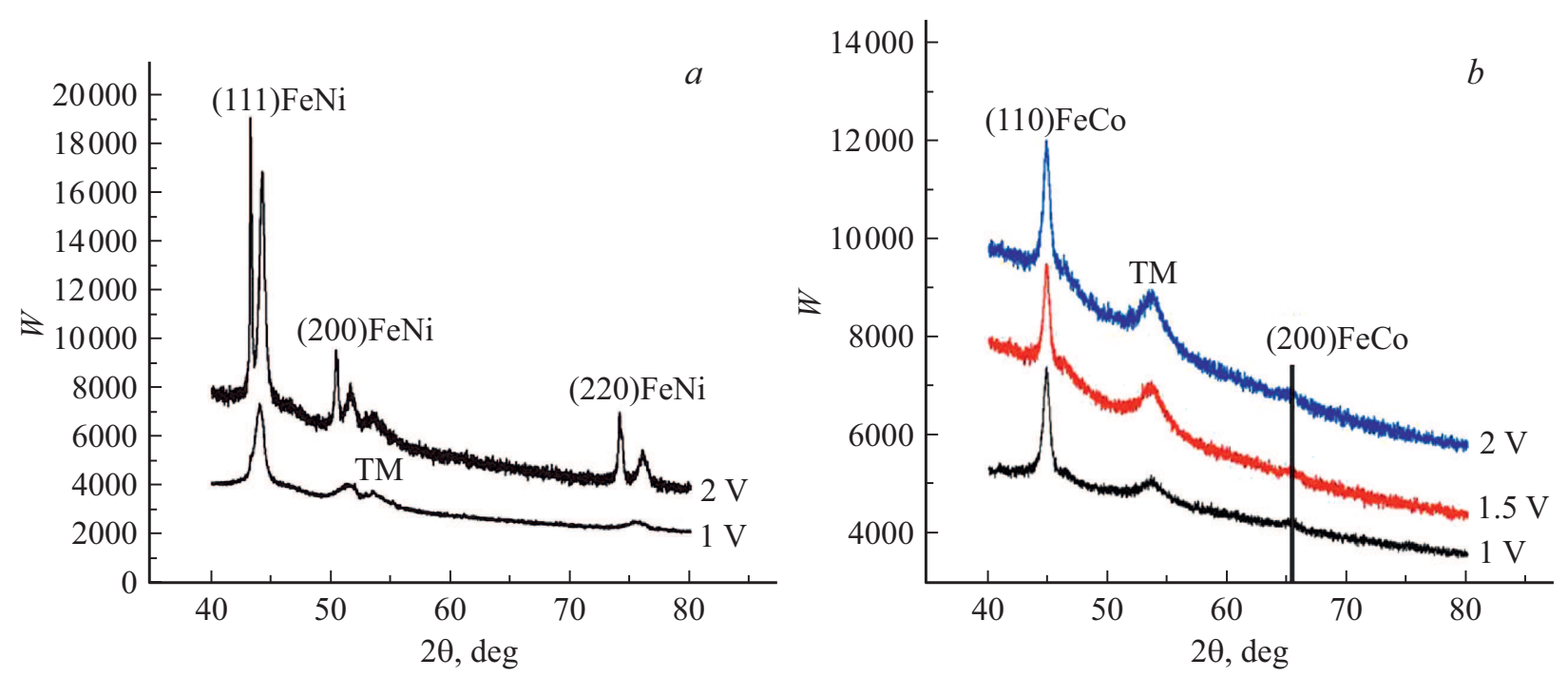

Рис. 5. Рентгенограммы $a$ ) FeNi HП, $b$ ) FeCo Н̈П.
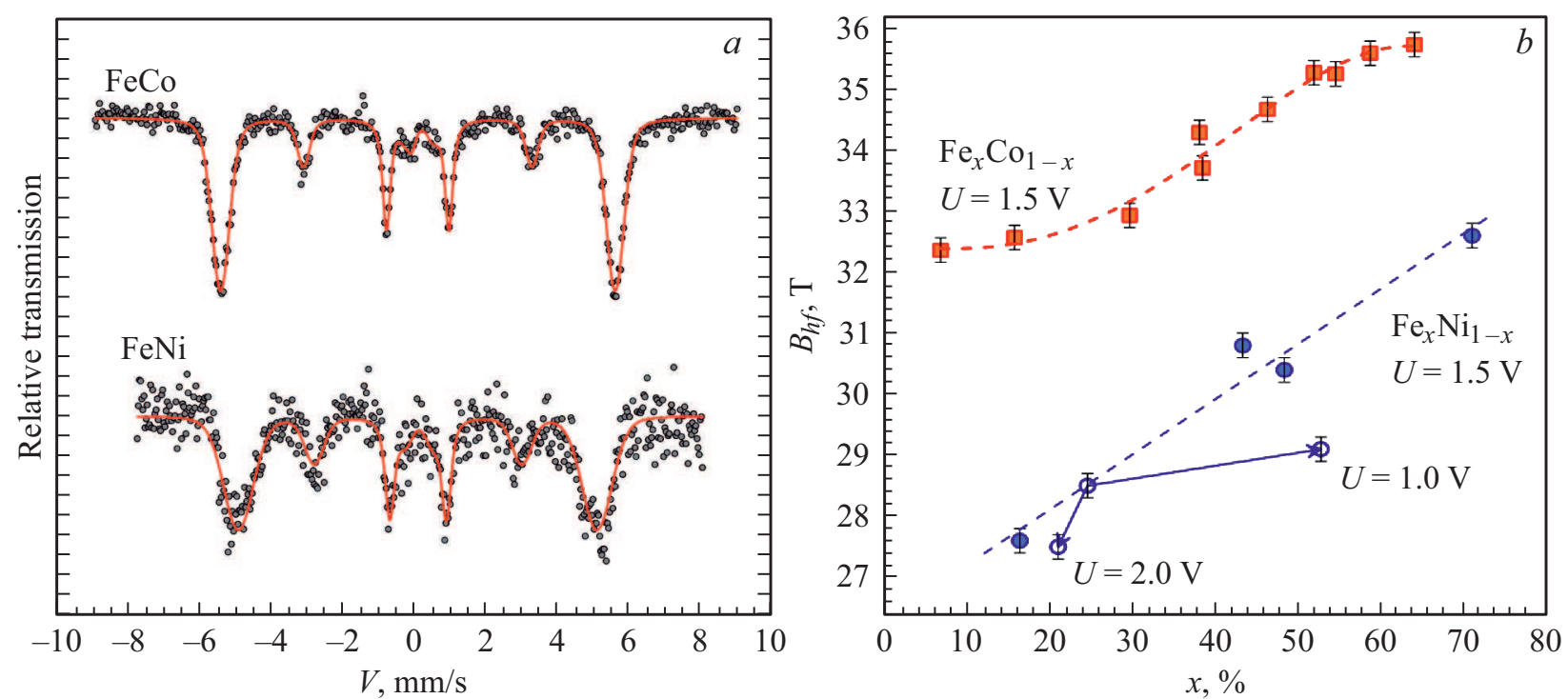

Рис. 6. а) Пример мёссбауэровских спектров на ядрах $57 \mathrm{Fe}$ полученных при потенциале осаждения $U=1.5 \mathrm{~V}$ НП твердых растворов $\mathrm{Fe}_{x} \mathrm{Co}_{1-x}$ и $\mathrm{Fe}_{x} \mathrm{Ni}_{1-x}$ при комнатной температуре. Сплошной линией показаны результаты математической обработки с помощью программы DISCVER [21,22]. b) Значения сверхтонкого магнитного поля $B_{h f}$ на ядрах ${ }^{57} \mathrm{Fe}$ для полученных при потенциале осаждения $U=1.5 \mathrm{~V}$ НП твердых растворов $\mathrm{Fe}_{x} \mathrm{Co}_{1-x}$ и $\mathrm{Fe}_{x} \mathrm{Ni}_{1-x}$ с различной концентраций железа $x$. Дополнительно пустыми кружочками показаны значения для $\mathrm{HП} \mathrm{Fe}_{x} \mathrm{Ni}_{1-x}$, полученных из электролита с относительным содержанием железа $25 \%$, при потенциалах осаждения $U=2.0,1.5$ и $1 \mathrm{~V}$. Пунктирные линии проведены на глаз для лучшего восприятия.

личающимся соотношением элементов. Сравнение двух дифрактограмм на рис. 5, $a$ позволяет предположить, что соотношение количества этих фаз меняется при изменении ростового напряжения. Последнее косвенно подтверждается данными элементного анализа, который показывает интегральное изменение состава по длине НП.

Анализ рентгенограмм на рис. 5, $b$ позволяет предположить, что НП из FеСо состоят из твердого раствора на основе железа. С увеличением ростового напряжения наблюдается изменение соотношения ин- тенсивностей пиков. Полуширина линий позволяет оценить линейный размер кристаллитов, который (как и в случае $\mathrm{FeNi}$ ) уменьшается с повышением ростового напряжения (и, соответственно, с повышением скорости роста).

Мёссбауэровская спектроскопия и магнитометрия. Для обоих типов образцов были измерены мёссбауэровские спектры, а также рассчитаны их сверхтонкие параметры, которые связаны с фазовым составом, структурой и магнитными свойствами массивов НП. Полученные результаты представлены на рис. 6. 


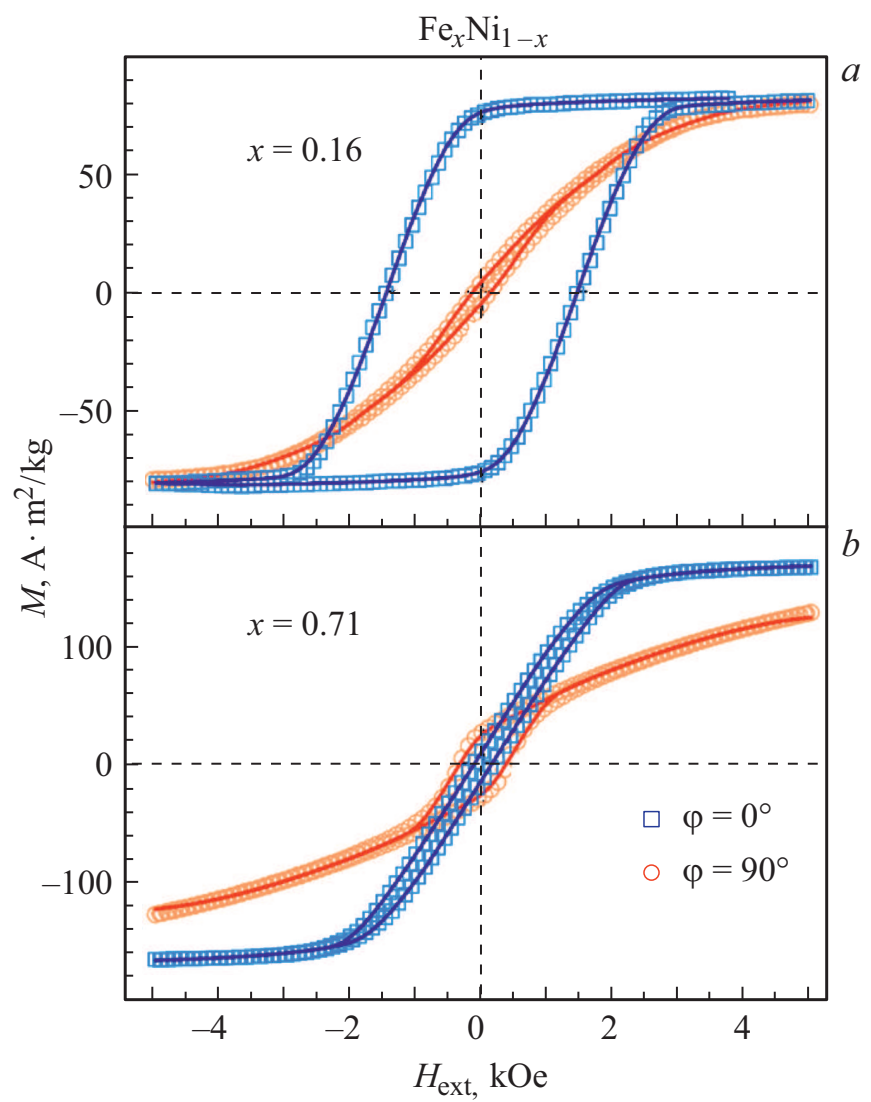

Рис. 7. Кривые намагниченности массивов $\mathrm{HП} \mathrm{Fe}_{x} \mathrm{Ni}_{1-x} \mathrm{c}$ минимальной $(a)$ и максимальной $(b)$ относительной концентрацией железа, полученных в порах с диаметром $100 \mathrm{~nm}$ при потенциале осаждения $U=1.5 \mathrm{~V}$. Экспериментальные данные показанные квадратами и кружками соответствуют ориентации внешнего магнитного поля $H_{e x t}$ параллельно $\left(\varphi=0^{\circ}\right)$ и перпендикулярно $\left(\varphi=90^{\circ}\right)$ оси НП соотвественно.

Спектры всех образцов массивов НП демонстрируют характерное магнитное расщепление и представляют собой слабоуширенные секстеты с соотношением интенсивностей спектральный линий, указывающим на спонтанную намагниченность НП вдоль их осей (рис. $6, a$ ). По результатам предварительного анализа экспериментальных спектров были построены зависимости сверхтонких полей $B_{h f}$ на ядрах ${ }^{57} \mathrm{Fe}$ для НП твердых растворов $\mathrm{Fe}_{x} \mathrm{Co}_{1-x}$ и $\mathrm{Fe}_{x} \mathrm{Ni}_{1-x}$ (см. рис. 6, $b$ ). Для образцов массивов НП обеих серий значения $B_{h f}$ возрастают при увеличении относительного содержания железа и близки к значениям $B_{h f}$ для кубических фаз ОЦК и ГЦК объемных сплавов железа с никелем и железа с кобальтом, известным из литературы [23]. Дополнительно было проведено сравнение мёссбаэуровских сверхтонких параметров $\mathrm{HП} \mathrm{Fe}_{x} \mathrm{Ni}_{1-x}$, выращенных из электролита с относительным $25 \%$ содержанием $\mathrm{Fe}$ при потенциалах осаждения $1,1.5$ и $2 \mathrm{~V}$. Обнаружено, что значения $B_{h f}$ в этих образцах составило 29.1, 28.5 и $27.5 \mathrm{~T}$ соответственно (см. рис. $6, b$ ), что согласуется с нашими данными элементного анализа об увеличении относительной концентрации железа в материале НП при понижении величины потенциала осаждения $U$. По-видимому, для более полного понимания и описания зависимости конечных свойств материала НП от величины потенциала $U$, а следовательно скорости процесса осаждения, необходимо проведение дальнейших экспериментов.

На рис. 7 представлены примеры кривых намагниченности массивов $\mathrm{HП} \mathrm{Fe}_{x} \mathrm{Ni}_{1-x}$ с минимальной и максимальной относительной концентрацией железа, полученных в порах с диаметром $100 \mathrm{~nm}$ при потенциале осаждения $U=1.5 \mathrm{~V}$. Петли гистерезиса носят явный ферромагнитный характер. Величины остаточной намагниченности и коэрцитивной силы значительно выше для НП с меньшей концентрацией железа, что хорошо согласуется с нашими результатами для $\mathrm{H \Pi} \mathrm{Ni}-\mathrm{Fe}$, осажденных в порах с диаметром 30 и $70 \mathrm{~nm}$ [20]. Хорошо видно, что все параметры резко меняются при изменении ориентации внешнего магнитного поля $H_{\mathrm{ext}}$ на $90^{\circ}$.

Результаты подробного анализа экспериментальных данных магнитных и мёссбауэровских измерений в рамках обобщенной модели Стонера - Вольфарта $[24,25]$ для всех синтезированных в рамках данной работы образцов НП твердых растворов $\mathrm{Fe}_{x} \mathrm{Co}_{1-x}$ и $\mathrm{Fe}_{x} \mathrm{Ni}_{1-x}$ будут представлены в наших следующих статьях, готовящихся к печати.

\section{4. Заключение}

В работе было показано, что структура и магнитные свойства массивов НП зависят от режима их получения (изменение состава электролита или потенциала осаждения). Исследованы зависимости изменение состава НП в зависимости от электролита, при этом в случае $\mathrm{FeNi}$ наблюдается аномальное со осаждение железа; обнаружено изменение состава НП по длине НП FeNi. Состав никельсодержащих образцов также сильно зависит от ростового напряжения - увеличение последнего приводит к уменьшению содержания железа. Для кобальтсодержащих НП получены другие зависимости. Так, их элементный состав практически совпадает с составом электролита и мало изменяется при изменении ростового напряжения. Получены мёссбауэровские спектры, доказывающие спонтанную намагниченность НП вдоль их осей. Впервые изучена зависимость сверхтонкого магнитного поля $B_{h f}$ от состава электролита. Так, показано, что значения $B_{h f}$ возрастают при увеличении относительного содержания железа и близки к значениям, характерным для кубических кристаллов. Магнитометрия показала, что НП с малой концентрацией железа обладают достаточно высокими значениями коэрцитивной силы и остаточной намагниченности. Таким образом показано, что изменяя условия синтеза НП можно варьировать магнитные свойства. 


\section{Финансирование работы}

Работы проводились при поддержке Минстерства образования и науки РФ в рамках выполнения работ по государственным заданиям ФНИЦ „Кристаллография и фотоника“ РАН и ФТИАН им. К.А. Валиева РАН, синтез нанопроволок и мёссбауэровские измерения выполнены при частичной поддержке гранта РФФИ 18-32-01066.

\section{Благодарности}

Авторы благодарны П.Ю. Апелю (ОИЯИ, Дубна) за предоставление образцов полимерных матриц.

\section{Конфликт интересов}

Авторы заявляют, что у них нет конфликта интересов.

\section{Список литературы}

[1] G.E. Possin. Rev. Sci. Instrum. 41, 772 (1970).

[2] S. Kawai, R.J. Ueda. Electrochem. Soc. 112, 32 (1975).

[3] S.K. Chakarvarti, J. Vetter. Nucl. Instr. Meth. Phys.Res. 62, 1, 109 (1991).

[4] J. Vetter, R. Spohr. Nucl. Instr. Meth. Phys. Res. 79, 1-4, 691 (1993).

[5] T.M. Whitney, J.S. Jiang, P.S. Searson, C.L. Chien. Science 261, 1316 (1993).

[6] C.R. Martin. Science 266, 23, 1961 (1994).

[7] H. Masuda, K. Fukuda. Science 268, 1466 (1995).

[8] N. Lupu. Electrodeposited Nanowires and Their Applications / Eds N. Lupu. InTech, Croatia (2010).236 p.

[9] Magnetic Nano- and Microwires: Design, Synthesis, Properties and Applications / Eds M. Va.zquez. Woodhead Publishing, Elsevier (2015).

[10] А.А. Давыдов, В.М. Волгин Электрохимия 52, 96, 905 (2016).

[11] D.J. Sellmyer, M. Zheng, R. Skomski. J. Phys.: Condens. Matter 13, R433 (2001).

[12] Y.P. Ivanov, J. Leliaert, A. Crespo, M. Pancaldi, C. Tollan, J. Kosel, A. Chuvilin, P. Vavassori. ACS Appl. Mater. Interfaces 11, 4 (2019)

[13] M. Vazquez, K. Pirota, J. Torrejon, D. Navas, M. HernandezVelez. J. Magn. Mater. 294, 174 (2005).

[14] J. Alonso, H. Khurshid, V. Sankar, Z. Nemati, M.H. Phan, E. Garayo, J.A. Garcia, H. Srikanth. J. Appl. Phys.. 117, 17D113 (2015).

[15] L. Elbaile, R.D. Crespo, V. Vega, J.A. Garcia. J. Nanomater. 13, 198453 (2012).

[16] D.C. Leitao, C.T. Sousa, J. Ventura, J.S. Amaral, F. Carpinteiro, K.R. Pirota, M. Vazquez, J.B. Sousa, J.P. Araujo. J. NonCrystal. Solids. 354, 5241 (2008).

[17] M. Almasi Kashi, A. Ramazani, S. Doudafkan, A.S. Esmaeily. Appl. Phys. A 102, 761 (2011).

[18] К.В. Фролов, Д.Л. Загорский, И.С. Любутин, М.А. Чуев, И.В. Перунов, С.А. Бедин, А.А. Ломов, В.В. Артемов, С.Н. Сульянов. Письма в ЖЭТФ 105, 5, 297 (2017).

[19] Д.Л. Загорский, К.В. Фролов, С.А. Бедин, И.В. Перунов, М.А. Чуев, А.А. Ломов, И.М. Долуденко. ФТТ 60, 11, 2075 (2018).
[20] K.V. Frolov, M.A. Chuev, I.S. Lyubutin, D.L. Zagorskii, S.A. Bedin, I.V. Perunov, A.A. Lomov, V.V. Artemov, D.N. Khmelenin, S.N. Sulyanova, I.M. Doludenko. J. Magn. Magn. Mater. 489, 165415 (2019).

[21] A.M. Afanas'ev, M.A. Chuev. J. Exp. Theor. Phys. 80, 560 (1995).

[22] M.A. Chuev. Dokl. Phys. 56, 318 (2011).

[23] C. Johnson, M.S. Ridout, T.E. Cranshaw. Proc. Phys. Soc. 81, 1079 (1963).

[24] A.M. Afanas'ev, M.A. Chuev, J. Hesse. J. Exp. Theor. Phys. 89, 533 (1999).

[25] M. Chuev, J. Hesse. J. Phys. Condens. Mater. 9, 506201 (2007).

Редактор Д.В. Жуманов 